\title{
Monitoramento de um talude rodoviário da BR-116 por uma aeronave remotamente pilotada
}

O monitoramento de taludes rodoviários constitui um recurso importante para evitar deslizamentos e possíveis tragédias causadas por movimentos de massa. A comparação de levantamentos topográficos realizados de forma sistemática e espaçados no tempo permitem a verificação nas mudanças da geometria de um talude. Com o avanço da tecnologia nos últimos anos, surgiram novos métodos para aquisição de dados, como por exemplo, a Aeronave Remotamente Pilotada ou Remotely Piloted Aircraft (RPA). O embarque de sensores em uma RPA viabiliza a obtenção de informações terrestres que podem ser utilizadas para gerar um modelo tridimensional do terreno. A comparação entre seções transversais de modelos obtidos em períodos distintos pode indicar locais de mudanças abruptas de declividade, que merecem maior atenção por apresentarem risco potencial de ruptura. O entendimento das variações da geometria de um talude é um recurso importante durante o monitoramento de encostas suscetíveis a deslizamentos. O presente trabalho apresenta a consolidação de uma proposta metodológica, com base no aerolevantamento, para a obtenção de modelos tridimensionais de um talude rodoviário localizado na BR-116, que terá sua geometria comparada ao longo do tempo visando seu monitoramento.

Palavras-chave: Talude Rodoviário; Aeronave Remotamente Pilotada; Modelo Digital do Terreno.

\section{Monitoring of a BR-116 road slope by remotely piloted aircraft}

\begin{abstract}
Monitoring road slopes is an important resource to prevent landslides and possible tragedies caused by mass movements. Comparison of topographic surveys performed systematically and spaced over time allows verification of changes in the geometry of a slope. With the advancement of technology in recent years, new methods for data acquisition have emerged, such as Remotely Piloted Aircraft (RPA). The shipment of sensors in an RPA enables the obtaining of terrestria information that can be used to generate a three-dimensional terrain model. Comparison between cross-sections of models obtained in different periods may indicate locations of abrupt declivity changes, which deserve greater attention because they present a potential risk of rupture. Understanding variations in slope geometry is an important feature when monitoring landslide-prone slopes. This paper presents the consolidation of a methodological proposal, based on the aerial survey, to obtain three-dimensional models of a road slope located on BR-116, which will have its geometry compared over time for its monitoring.
\end{abstract}

Keywords: Road Slope; Remotely Piloted Aircraft; Digital Terrain Model.

Topic: Tecnologia, Modelagem e Geoprocessamento

Reviewed anonymously in the process of blind peer.
Received: 30/06/2019

Approved: $\mathbf{3 0 / 0 7 / 2 0 1 9}$
Jhonatan Tilio Zonta (D)

Universidade Federal do Paraná, Brasil

http://lattes.cnpq.br/7848272030045448

http://orcid.org/0000-0002-9652-0507

ihonatanzonta@hotmail.com

Larissa de Brum Passini (iD

Universidade Federal do Paraná, Brasil

http://lattes.cnpq.br/8422646567052379

http://orcid.org/0000-0002-8947-4602

larissapassini@hotmail.com

\section{Cristhyano Cavali da Luz (iD)}

Universidade Federal do Paraná, Brasil

http://lattes.cnpq.br/2689181976828005

http://orcid.org/0000-0002-2688-3863

crisccluz@hotmail.com
Dyeison Cesar Mlenek (iD

Universidade Federal do Paraná, Brasil

http://lattes.cnpq.br/2557613431436491

http://orcid.org/0000-0003-1289-3486

dyeison.mlenek@hotmail.com
Referencing this:

ZONTA, J. T.; PASSINI, L. B.; LUZ, C. C.; MLENEK, D. C.. Monitoramento de um talude rodoviário da BR-116 por uma aeronave remotamente pilotada. Revista Ibero-Americana de Ciências Ambientais, v.10, n.4, p.373-384, 2019. DOI: http://doi.org/10.6008/CBPC2179$\underline{6858.2019 .004 .0029}$

DOI: 10.6008/CBPC2179-6858.2019.004.0029 


\section{INTRODUÇÃO}

A infraestrutura de transportes caracteriza-se como uma importante via de crescimento e desenvolvimento econômico e social de uma nação. O modal rodoviário, predominante na esfera nacional, permite a movimentação de pessoas e cargas, tornando-se vital para o crescimento da economia de um país (BOCK et al., 2015). Entretanto, tem-se verificado uma crescente preocupação com questões da segurança rodoviária, cujos impactos podem ocorrer tanto na sua fase de implantação quanto na operação. Dentre os eventos preocupantes que envolvem as encostas e taludes de uma rodovia estão os movimentos gravitacionais de massa. Segundo Montoya (2013), os deslizamentos e movimentos de massa em geral são responsáveis pelos maiores níveis de prejuízos relacionados à fenômenos naturais.

Para que incidentes relacionados à movimentação de massa em maciços rodoviários possam ser minimizados ou evitados, surge a necessidade do entendimento e reconhecimento cada vez mais amplo dos mecanismos e das condições que levam o surgimento das instabilidades em taludes. Entretanto, os processos deflagradores de movimentação de massa são complexos e demandam estudos que permitam um entendimento integral do problema. Nesse sentido, o monitoramento de taludes rodoviários com problemas de estabilidade é um procedimento que pode ajudar a entender a dinâmica da movimentação de massa no local, bem como apontar medidas corretas de controle.

Dentre as diversas tecnologias utilizadas para a análise e mapeamento do terreno, as Aeronaves Remotamente Pilotadas (Remotely Piloted Aircraft - RPA), surgem como uma alternativa rápida e promissora para obtenção de um Modelo Digital do Terreno (MDT) (LUCIEER et al., 2012; BORGES et al., 2017). A modelagem sistemática da geometria de um talude torna possível realizar comparações ao longo do tempo e assim monitorar se ele está ou não em estabilidade.

O uso de uma RPA para tal finalidade é possível, pois a aeronave permite acoplar uma câmera fotográfica, capaz de obter fotografias aéreas, as quais são utilizadas para gerar um MDT. O desempenho em áreas de difícil acesso e a flexibilidade nas manobras vêm viabilizando a introdução gradual desde 1980 dessa tecnologia nas diversas áreas da Engenharia (DISPERATI, 1991; MELESSE, 2007; WENG, 2010; ABREU, 2014), fomentando pesquisas relacionadas a seu uso e criando a necessidade de estudos mais detalhados que permitam explorar ao máximo a sua aplicabilidade.

\section{MATERIAIS E MÉTODOS}

\section{Área de estudo}

O talude escolhido localiza-se no km552 da pista norte da rodovia Régis Bittencourt (BR-116), situado próximo da cidade de Barra do Turvo, no estado de São Paulo. Este talude situa-se na Serra Pelada, a qual pertencente à cadeia montanhosa da Serra do Mar, entre as cidades de Curitiba (PR) e São Paulo (SP) (figura 1). Pontes (2017) realizou o levantamento dos principais taludes da região, suas características geométricas, histórico de deslizamentos e análise de mapas de declividade. A partir de uma análise integrada dos atributos supramencionados, o talude do km552 apontou a existência de uma instabilidade no local, pois, apesar das 
medidas de contenção adotadas (retaludamento e gabião em sua base) ainda há indícios de movimentação gravitacional de solo.

A figura 2 apresenta as linhas topográficas obtidas através de levantamentos realizados nos anos de 2011 e 2017. A região circular delimita uma área de movimentação considerada crítica, onde identifica-se que o talude perdeu a configuração pretérita de retaludamento e apresentou a formação de uma cunha de ruptura, possivelmente associada a movimentos de rastejo. A fim de compreender o entendimento dos movimentos de massa, foi realizada a comparação das declividades entre os anos de 2011 e 2017.

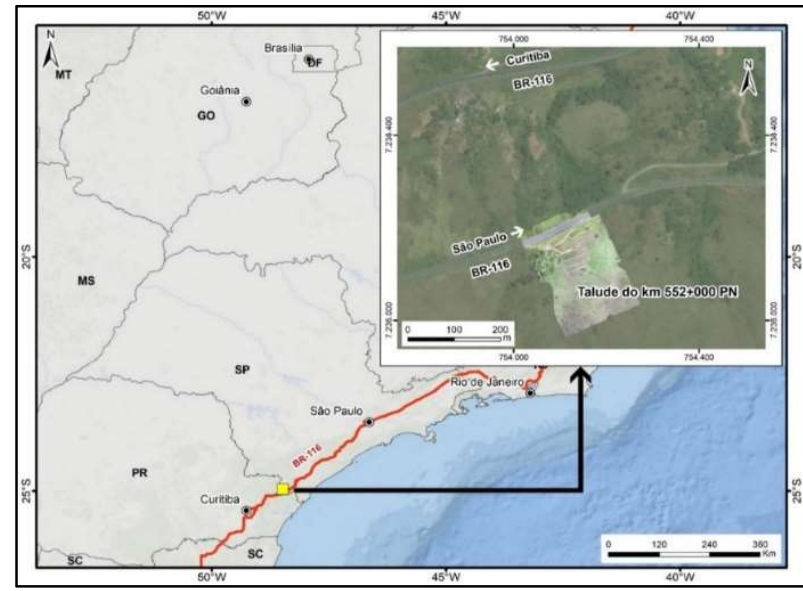

Figura 1: Localização das áreas de estudo.

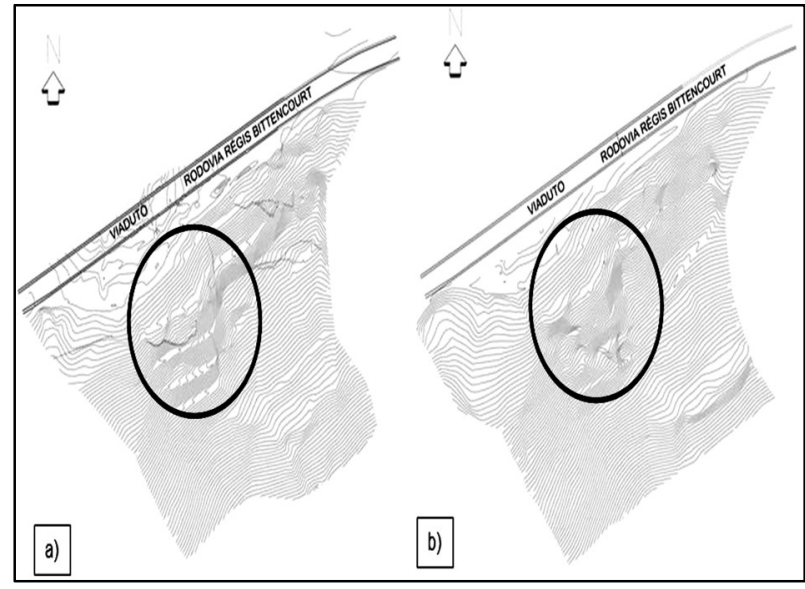

Figura 2: Linhas topográficas do talude nos anos de (a) 2011 e (b) 2017. Fonte: Trevizolli et al. (2018).

Tabela 1: Equipamentos e materiais utilizados no estudo.

\begin{tabular}{|c|c|}
\hline Qtd & Materiais \\
\hline 1 & Microcomputador Intel Core i-7 @ 3,5 GHz - 16 Gb Ram Ge-Force GTX 780 Ti - HDD 1Tb; \\
\hline 1 & Software fotogramétrico de código fechado - Agisoft Photo Scan \\
\hline 1 & Professional Version 1.0.4 (64 bits) 2014; \\
\hline 2 & RPA - Inspire 1 - Camera Zenmuse X5R, 16 MP. \\
\hline 1 & Receptores GNSS L1/L2 Foif A 30 (RTK); \\
\hline 1 & Software SIG - ArcGIS v.10.2.2.3552 \\
\hline 1 & AutoCad Civil 3D - Autodesk v 12.0.842.0 \\
\hline
\end{tabular}

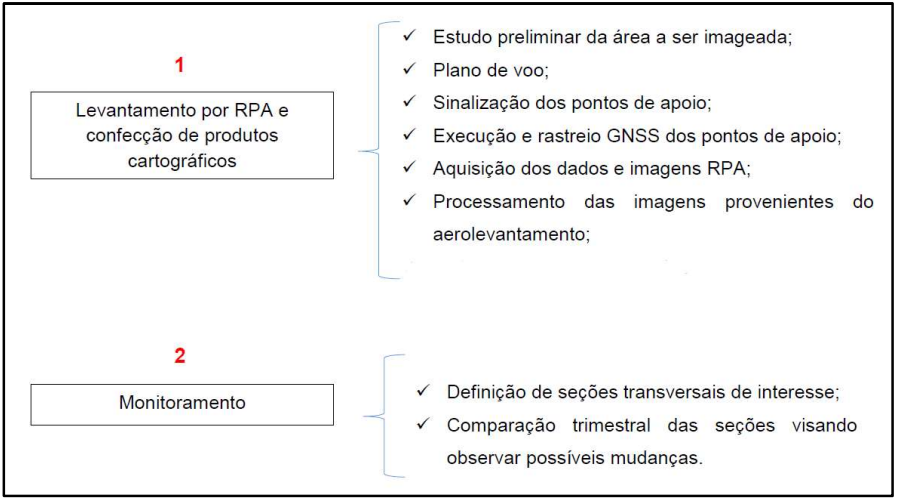

Figura 3: Fluxograma dos métodos empregados.

Para o desenvolvimento deste trabalho foram utilizados os equipamentos e materiais descritos na Tabela 1. Para execução desta pesquisa as etapas foram divididas em 'Levantamento por RPA e confecção de produtos cartográficos' e 'Monitoramento', conforme apresentado pela figura 3. Foi estabelecido um monitoramento trimestral, durante o período de 1 ano, sendo os levantamentos aéreos realizados nos meses de novembro/2017, fevereiro/2018, maio/2018, agosto/2018 e novembro/2018. A frequência de 
levantamentos justifica-se pela necessidade do monitoramento das possíveis movimentações de massa que possam ocorrer durante um ano hidrológico.

\section{Estudo preliminar da área}

Algumas análises preliminares são de extrema importância, no que se refere ao planejamento adequado da trajetória em que a RPA vai executar. Essas análises foram realizadas por meio de observações na área do talude estudado com o intuito de se obter a delimitação da área de interesse e a verificação de possíveis problemas para o imageamento, tais como: obstáculos naturais (picos, cumes), cabos elétricos, etc..

\section{Plano de voo}

O planejamento do voo da RPA foi ajustado de acordo com Disperati (1991) e ao fator "relevo", pois a altura máxima alcançada no voo é de 150 metros, porém o talude estudado faz parte de uma encosta de mais de $150 \mathrm{~m}$ de altura (limitação de fábrica do equipamento). Dessa maneira o plano de voo foi realizado de maneira a cumprir o imageamento dentro da área de interesse, visto que quando se tem variações de altitude com menos de 50m ocorrem implicações nas suas sobreposições. Portanto, nos segmentos em que a altitude de voo era menor que esse valor houve uma redução da velocidade da RPA (para a sobreposição adequada das imagens). Ademais, certificou-se das condições meteorológicas e atmosféricas no dia da atividade, pois o principal fator para a boa tomada das fotografias é em dias de sol e sem vento.

\section{Sinalização dos pontos de apoio}

A pré-sinalização é uma marcação artificial feita no terreno com a finalidade de ser identificada na imagem ou fotografia aérea para o georreferenciamento. A localização das marcas (Figura 4) foi planejada de acordo com o plano de voo da área estudo e seguiu as orientações de Costa et al. (2012) e Luz (2015). Houve uma distribuição estratégica dos pontos de apoio e amarração dos blocos, sobretudo em locais que fossem visivelmente fáceis de identificar, como no final e intersecções de canaletas.

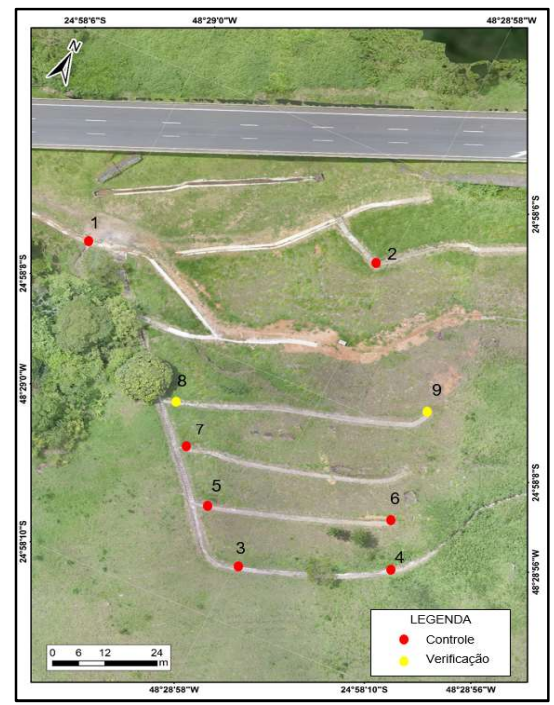

Figura 4: Pontos de apoio selecionados em escritório. 
A figura 5 ilustra a sinalização executada com tinta de cor laranja e preta em forma de ' $x$ ', além disso, a coloração foi escolhida pela sua diferente refletância comparada ao local escolhido. A figura 6 ilustra uma fotografia aérea e, em seu detalhe, a possibilidade de identificação das marcas, com identificação da présinalização nas fotografias aéreas.

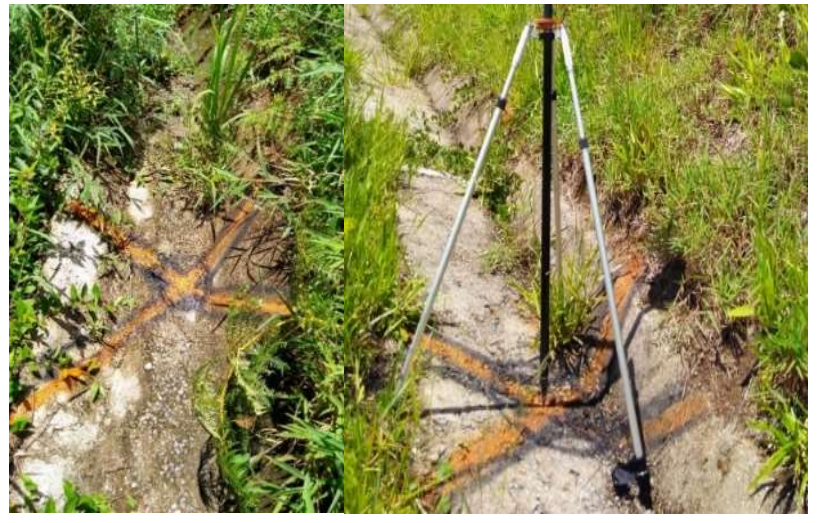

Figura 5: Pré-sinalização da área de interesse com tinta de cor laranja e preta.

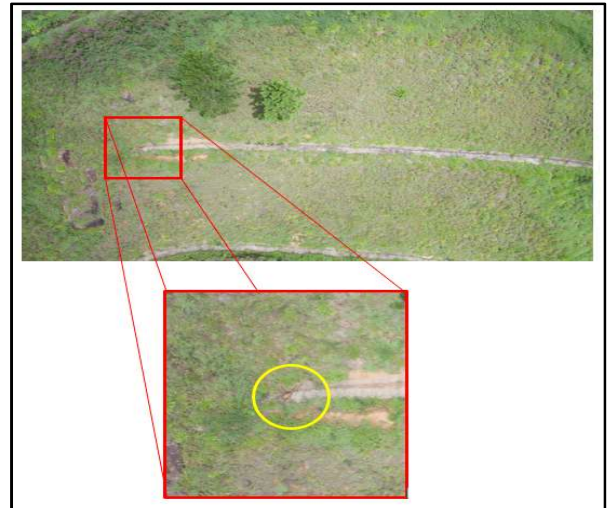

Figura 6: Identificação da pré-sinalização nas fotografias aéreas.

\section{Execução do rastreio dos pontos de apoio do terreno}

Foram rastreados com receptor (Global Navigation Satellite System ou Sistema de Navegação Global por Satélite (GNSS) um total de 7 pontos de apoio e 2 pontos de verificação, sendo todas as sinalizações implantadas antes do sobrevoo da área a ser estudada. Os pontos de apoio são utilizados para fazer a relação entre o sistema de coordenadas da imagem com o sistema de coordenadas do terreno, em outras palavras são pontos de referência no solo que são utilizadas no processamento das imagens aumentando assim a precisão do modelo.

Conforme Costa et al. (2012), o intuito dessa sinalização é proporcionar uma maior precisão das coordenadas dos pontos de apoio, dos quais serão conhecidas as exatas posições planimétricas no terreno e suas respectivas altitudes, possibilitando assim a posterior avaliação geométrica e validação dos produtos cartográficos diante da topografia já executada no local. Já os pontos de verificação representam as mesmas características dos pontos de apoio, a diferença é a sua utilização, os quais são utilizados para medir a acurácia de um levantamento comparando as coordenadas obtidas no modelo com as coordenadas do terreno. A Figura 7 apresenta o rastreio dos pontos pré-sinalizados, através do posicionamento dos receptores nas marcas artificiais.
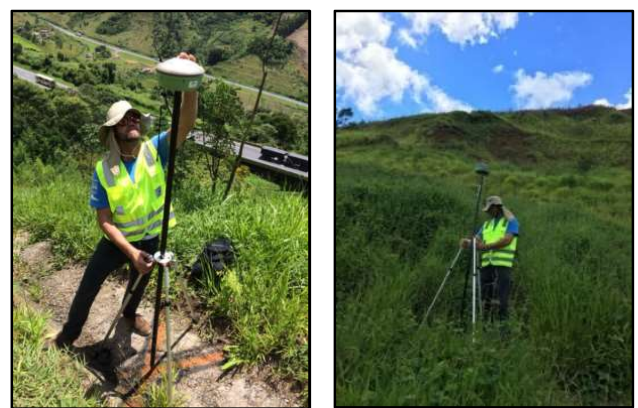

Figura 7: Rastreio GNSS realizado na área de estudo. 


\section{Aquisição dos dados e imagens através da RPA}

Para obtenção das fotografias aéreas foi utilizada uma RPA, modelo Inspire 1 (Figura ), fabricado pela DJI technology, o qual possui um sistema de transmissão de vídeo HD, rotação de $360^{\circ}$ e uma câmera de 4 K. Além disso, o equipamento possui um GPS interno possibilitando adicionar coordenadas geográficas a cada fotografia.

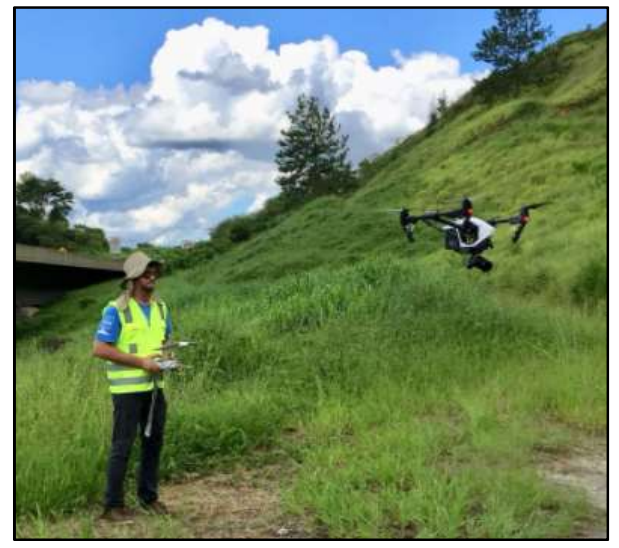

Figura 8: RPA modelo Inspire 1.

\section{Processamento das imagens provenientes do aerolevantamento}

O processamento das imagens obtidas com a RPA foi implementado com base na sequência de procedimentos propostos por Luz (2015), sendo as etapas: seleção e filtragem das fotografias; processamento dos dados com software; alinhamento das fotografias; construção da nuvem de pontos; e construção da malha poligonal 3D. Todas as etapas aqui detalhadas visaram utilizar metodologias clássicas associadas ao processamento de imagens por meio da utilização de um software aerofotogramétrico específico para plataformas autônomas.

\section{Seleção e filtragem das fotografias}

A primeira etapa corresponde a seleção e a filtragem das fotografias. A seleção eliminou o número excessivo de fotografias repetidas, decorrentes da alta taxa de sobreposição longitudinal, e também as fotografias com problemas de falta de iluminação natural, ou seja, com sombras. A filtragem foi realizada manualmente, antes das fotografias serem adicionadas à ferramenta computacional, excluindo aquelas que apresentaram problemas de qualidade. Essa seleção reduz possíveis erros durante a fase de processamento dos dados.

\section{Processamento dos dados com software}

Para este trabalho, as fotografias foram processadas através de algoritmos computacionais de classificações de padrões e reconstrução tridimensional do terreno, oriundos do software de código fechado Agisoft PhotoScan Professional Edition Version 1.0.4, ano de 2014. O objetivo do processamento de fotografias aéreas com o Photoscan é construir um modelo digital do terreno (MDT) e compreendeu quatro fases principais descritas. 


\section{Alinhamento das fotografias}

Após a seleção e filtragem, as fotografias foram adicionadas no software e alinhadas através de um algoritmo que localiza os pontos homólogos entre elas. Por essa razão, o planejamento de voo foi elaborado para que houvesse uma sobreposição das fotografias maior que $80 \%$. O programa realiza a leitura das informações armazenadas nas imagens, identificando padrões comuns mediante algumas 'características principais'. A técnica que o software utiliza consiste em estabelecer uma relação geométrica entre duas vistas similares, quando cada cena possui o seu centro de projeção ${ }^{1}(\mathrm{CP})$ e estes não são coincidentes. Cada par de imagens capturado representa duas perspectivas diferentes de uma mesma cena estática (LUZ, 2015). Esta etapa resultou em um grande tempo de processamento, por meio da rotina computacional.

\section{Construção da nuvem de pontos}

O conhecimento das coordenadas aproximadas de cada fotografia, permitiu a obtenção das orientações externas, por meio do ajuste de feixes. Nesta etapa, obteve-se uma densa nuvem de 16.167.048 pontos homólogos (pontos de ligação) entre as fotografias (Figura 9). Nesta etapa, também foi realizada adição dos 7 pontos de apoio rastreados em campo. Este processo é realizado automaticamente pelo Agisoft. A localização exata dos marcadores (markers) em cada fotografia é ajustada manualmente, movendo-se os marcadores para o local dos pontos sinalizados com tinta de cor laranja e preta em forma de ' $x$ ' (Figura 10).

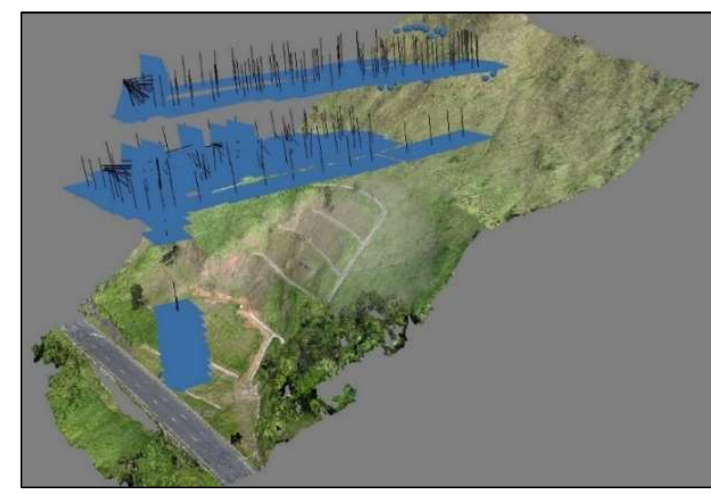

Figura 9: Obtenção da nuvem de pontos homólogos a partir do alinhamento das fotografias aéreas (representadas pela cor azul).

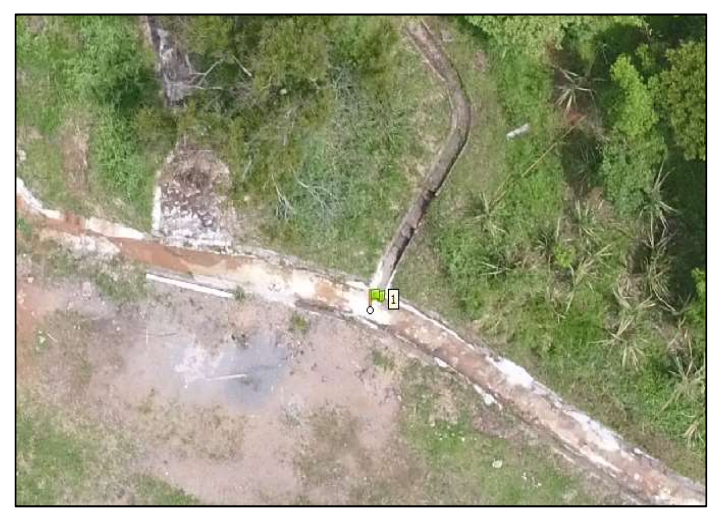

Figura 10: Ajustamento dos marcadores (destacado).

\section{Construção da malha poligonal 3D}

Na sequência, gerou-se uma grade triangular irregular (Triangulated Irregular Network (TIN). Essa etapa é realizada através do método dos feixes perspectivos (bundle block adjustment), permitindo que todas as imagens que compõem o espaço imagem ${ }^{2}$ e todos os pontos fotogramétricos contidos nestas imagens fossem tratados em um único processo. Tal método é detalhado no trabalho de Silveira (2004).

De acordo com Felgueiras (2001), o modelo da grade irregular TIN é mais propício para a inclusão das feições topográficas, ou seja, representa melhor superfícies não homogêneas com variações locais

\footnotetext{
${ }^{1} \mathrm{O}$ centro de projeção em uma câmera é o ponto fixo de onde partem ou por onde passam as projetantes.

2 É o espaço compreendido pelo plano do negativo e o ponto nodal posterior.
} 
acentuadas, pois apresenta uma estrutura de dados mais complexa, onde os vértices dos triângulos pertencem ao próprio conjunto amostral. Cada vértice da rede é procedente da altitude advinda da equação de colinearidade. A fototriangulação, através de uma grade irregular TIN para o modelo, gerou 2.327.166 triângulos (figura 11). Ao final desta etapa é obtido o Modelo Digital de Superfície (MDS), o qual encontrase integrado às fotografias e com textura. Segundo Felgueiras (2001), a técnica aplicada na texturização é denominada de 'ray tracing', a qual integra os pixels da imagem utilizada ao modelo (Figura 12).

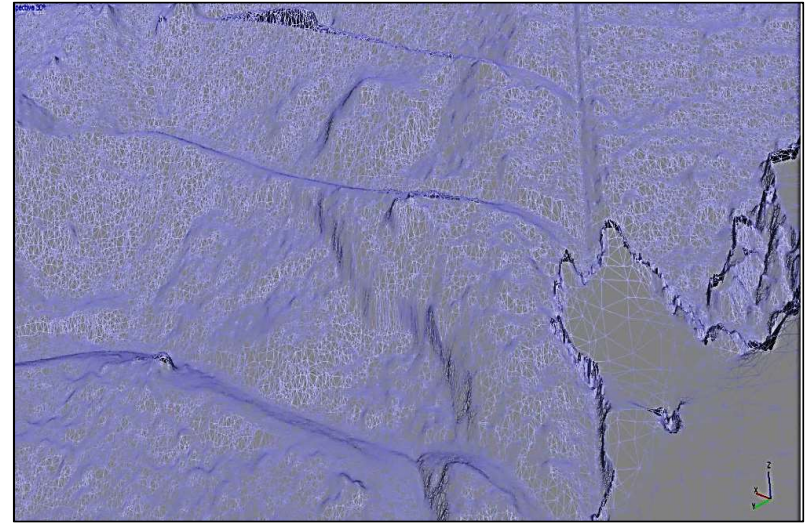

Figura 11: Grade TIM.

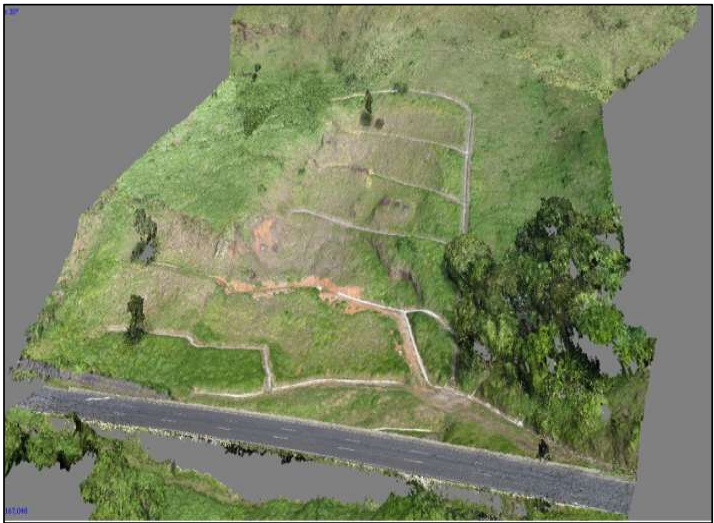

Figura 12: Modelo digital de Superfície.

\section{Obtenção do MDT}

O MDT pode ser obtido por meio de um processo de filtragem do MDS, que consiste na remoção dos pontos que não pertencem à superfície do terreno, ou seja, aqueles que se encontram acima do solo, tais como construções, árvores, entre outros. A figura 13 demonstra em cinza os pontos removidos do modelo e em marrom o MDT.

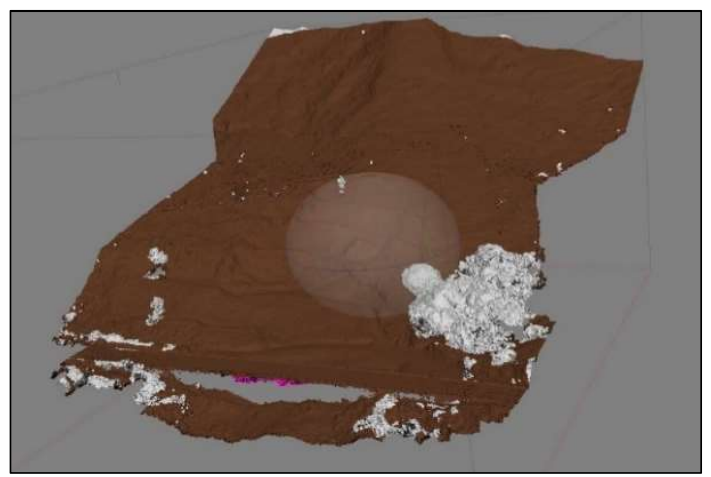

Figura 13: Obtenção do MDT.

\section{Monitoramento de movimentos de massa}

Segundo Felgueiras (1997), a partir de um MDT pode-se criar gráficos de perfis do fenômeno estudado ao longo de uma trajetória. Os pontos do perfil são determinados pela intersecção de cada seção com as arestas do MDT e representam a variação do fenômeno estudado em função da distância planar percorrida em um trajeto predefinido. Além disso, Felgueiras (1997) menciona a possibilidade de adição de mais de um perfil no mesmo gráfico visando a comparação entre eles (figura 14). 


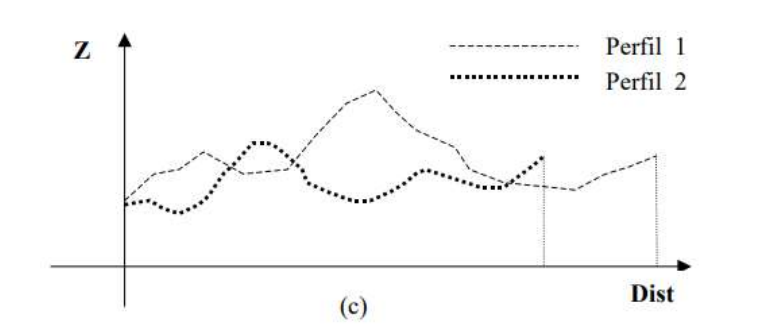

Figura 14: Comparação de perfis

De posse dos MDT's, obtidos através das investigações realizadas nos meses de novembro/17, fevereiro/18, maio/18, agosto/18 e novembro/18, foram traçadas 5 seções transversais em cada um deles, de maneira a abranger todas as regiões do talude, conforme a figura 15. As seções localizadas nas extremidades (Seção A-A e Seção C-C) estão fora da área crítica, já as seções centrais (Seção B-B, Seção D-D e Seção E-E) estão localizadas nas regiões mais críticas do talude. Sendo assim, o monitoramento proposto no presente trabalho consiste em comparações dos perfis gerados pelos 5 levantamentos, os quais representam a geometria do talude ao longo do tempo. Os resultados serão apresentados a seguir.

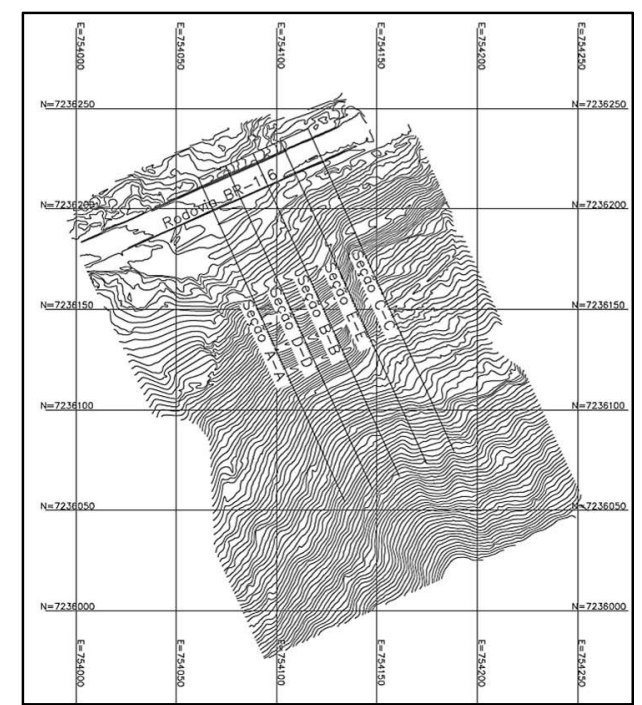

Figura 15: Localização das seções transversais (curvas de nível proveniente do aerolevantamento).

\section{RESULTADOS}

Para monitorar eventuais movimentações de massa no talude, foram realizadas análises comparando as variações dos perfis gerados em cada levantamento. Tais perfis representam a geometria do talude e as comparações ao longo do tempo permitem inferir se sobre a estabilidade do maciço. São apresentados os perfis resultantes do monitoramento trimestral para cada seção, sendo que a Figura 16 apresenta os perfis para a seção A-A; a figura 17 apresenta os perfis para a seção B-B; a figura 18 apresenta os perfis para a seção C-C; a figura 19 apresenta os perfis para a seção D-D; e a figura 20 apresenta os perfis para a seção E-E.

Na seção A-A os perfis de monitoramento para cada mês apresentaram alterações na significância de aproximadamente 1,0 metro, exceto no pé do aterro, onde nos meses de maio e agosto foi observado um acréscimo das cotas $(\sim 3,5 m)$. Estes acréscimos no pé do aterro também foram observados nas seções $D-D$, B-B e E-E, porém, em magnitudes menores. Os perfis de monitoramento localizados nas regiões mais críticas 
(seção B-B, D-D e E-E) também apresentaram poucas variações de cota ao longo do tempo $(\sim 1,0 \mathrm{~m})$ e são relativamente semelhantes.

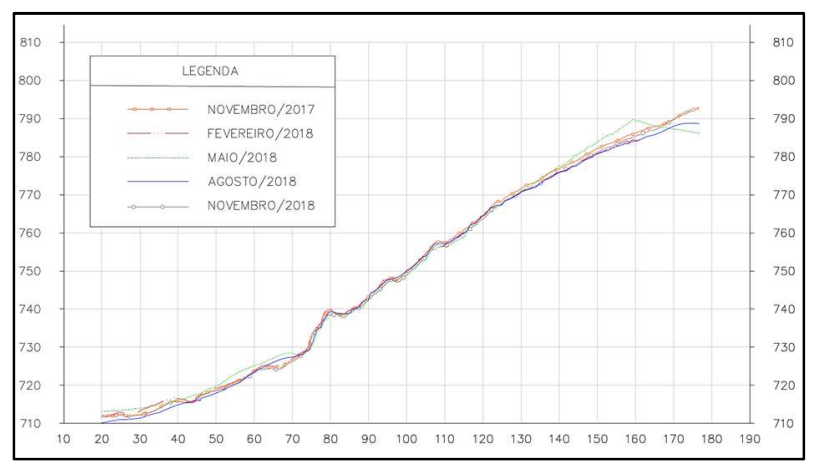

Figura 16: Comparação dos perfis na seção A-A.

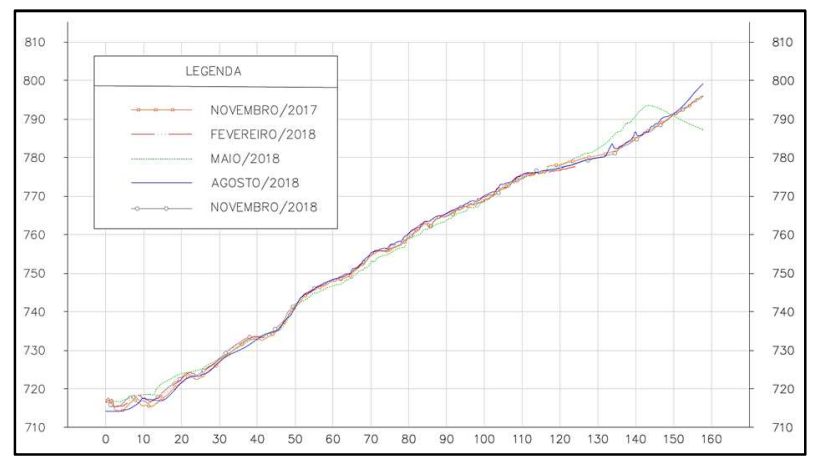

Figura 18: Comparação dos perfis na seção C-C.

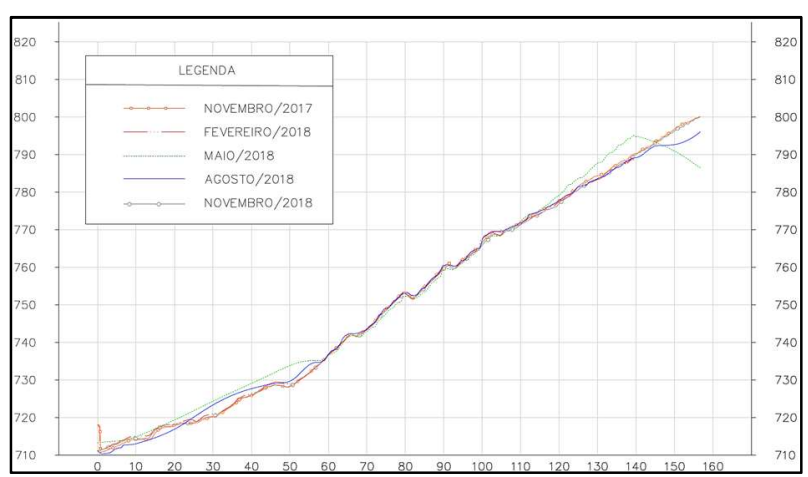

Figura 17: Comparação dos perfis na seção B-B.

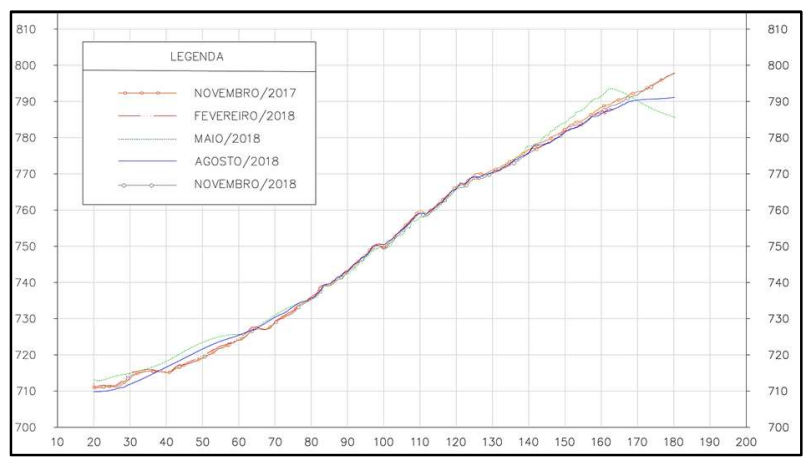

Figura 19: Comparação dos perfis na seção D-D.

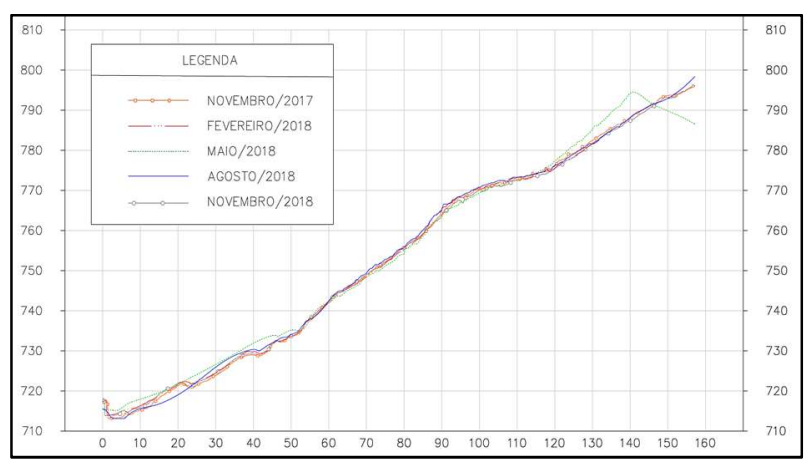

Figura 20: Comparação dos perfis na seção E-E.

O perfil C-C, localizado na última extremidade transversal à rodovia (sentido São Paulo) e fora da área crítica foi o que apresentou as menores variações entre os meses de monitoramento. De acordo com as seções apresentadas, não foi possível perceber uma mudança abrupta da geometria do talude durante o período de monitoramento. Além disso, as pequenas variações observadas entre os levantamentos em cada seção não seguem um padrão.

\section{DISCUSSÃO}

De maneira geral, verificou-se um bom detalhamento do terreno nos perfis gerados através do aerolevantamento e pôde-se visualizar com clareza a existência de banquetas, canaletas de drenagem ou pequenas variações no terreno, sendo vantagens do monitoramento por uma RPA. Em se tratando de um 
monitoramento das feições geométricas de um talude com grandes dimensões e de difícil acesso, o levantamento em campo através de uma RPA e com alguns pontos de apoio mostrou-se menos oneroso, se comparado a um levantamento topográfico. Ganhando-se assim agilidade no processo de levantamento.

Nas cotas mais superiores do talude (eixo x maior do que 140m), observou-se uma discrepância dos levantamentos, os quais justificam-se pela ausência de pontos de apoio nesses locais. Entretanto, estes locais estão fora da zona crítica do estudo. Considerando que os modelos utilizados para a comparação são obtidos a partir de imagens aéreas, é possível inferir que tais variações observadas entre os meses de monitoramento são causadas pela diferença da altura da vegetação. Tal diferença pôde ser vista em campo e também pelo aspecto das imagens, obtidas em diferentes épocas do ano, conforme apresentado na figura 21.

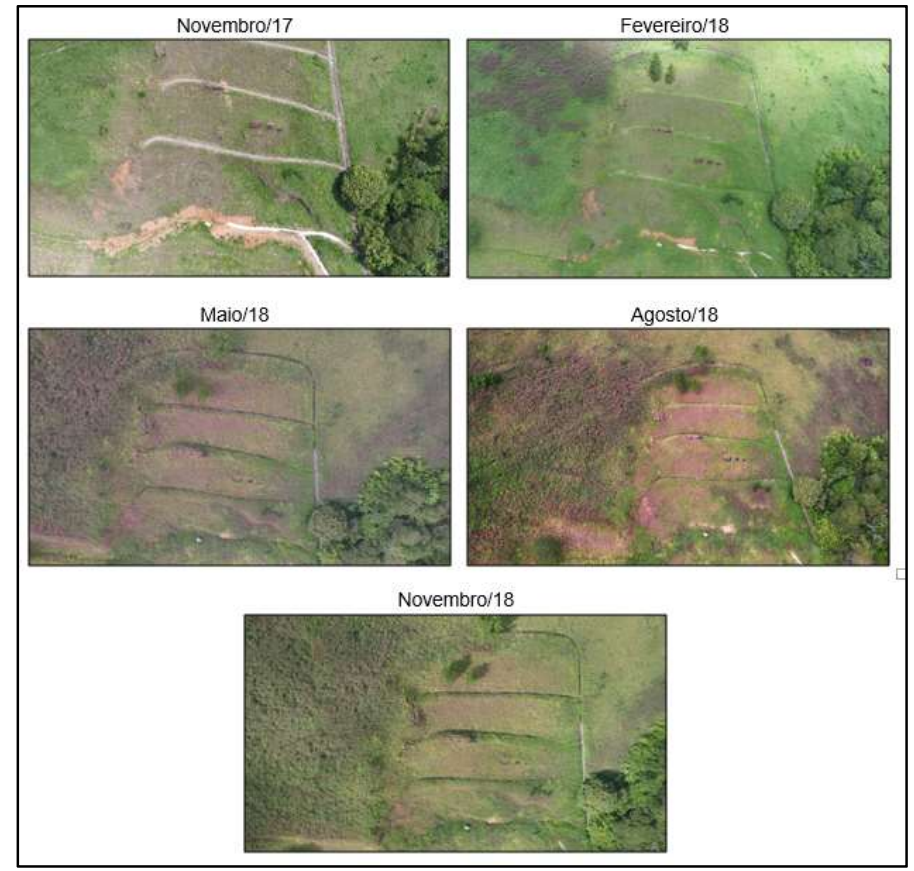

Figura 21: Diferença da vegetação entre os levantamentos.

Em conclusão, para o monitoramento das feições geométricas de um talude por meio de fotografias aéreas é fundamental manter a roçada no local. Outra opção é fazer a substituição da câmera fotográfica convencional por um equipamento de Varredura a Laser Terrestre. Tal sistema possibilita manipular e separar os primeiros pulsos retornados (vegetação) dos últimos pulsos retornados (terreno).

\section{CONCLUSÕES}

Em taludes rodoviários com grandes declividades e que podem apresentar algum risco ao usuário, surge a necessidade de se monitorar e avaliar a segurança desses locais com maior detalhamento, além disso, são fundamentais ações que possam proporcionar maior estabilidade ao maciço. Para tanto, a presente pesquisa procurou buscar tecnologias e métodos que pudessem acrescentar informações para o entendimento e tomada de decisão de problemas relacionados a esse tipo de situação.

O uso de aeronaves para o sensoriamento remoto pode ser utilizado para as mais diversas áreas da pesquisa, já que não faltam opções de sensores que podem ser embarcados em diferentes tipos de RPA. Entretanto, em se tratando de obtenção de informações de um talude, vários cuidados devem ser tomados 
desde o levantamento até o processamento dos dados para que os produtos estejam alinhados à sua aplicação.

Dentre os principais elementos que tiveram influência no processamento do modelo tridimensional do talude estudado, destacam-se: uma boa distribuição dos pontos de apoio, uma seleção das imagens e um ajustamento preciso dos marcadores (markers), este último sendo fundamental para a atenuação dos erros oriundos do processamento. Portanto, deve-se levar em consideração o tamanho do talude a ser estudado, pois quanto maior o talude mais fotos serão necessárias e assim mais trabalho de ajustamento manual terá que ser realizado, dependendo da precisão requerida.

Para o monitoramento das feições geométricas do talude, não foi verificada nenhuma mudança abrupta na geometria e sim pequenas variações dos perfis de cada levantamento; entretanto, tais alterações podem ter sido ocasionadas pela vegetação presente no talude nos dias em que houve levantamento. Inferese isto porque os levantamentos foram realizados em diferentes estações do ano e para processamento do modelo tridimensional do terreno são utilizadas imagens que podem captar pequenas variações da vegetação. Portanto, o método utilizado no presente trabalho é praticável em taludes sem vegetação ou em taludes que possuam uma roçada periódica.

\section{REFERÊNCIAS}

ABREU, K. M. P.; COUTINHO, L. M.. Sensoriamento remoto aplicado ao estudo da vegetação com ênfase em índice de vegetação e métricas da paisagem. Vértices, Campos dos Goytacazes, v.16, n.1, 2014.

BOCK, C. P.; PEREIRA, G. Q. O.; ESTENDER, A. C.. Transporte Rodoviário de Cargas: A Complexa Cadeia Logística. In: CONGRESSO METODISTA DE INICIAÇÃO E PRODUÇÃO CIENTÍFICA: SEMINÁRIO DE EXTENSÃO, 17. Anais. São Paulo, 2015.

BORGES, R. O.; FAZAN, A. J.; SOBRAL, L. T.; RIBEIRO, R. F.; LANZA, D. S.. Utilização de Drones de Pequeno Porte como Alternativa de Baixo Custo para Caracterização Topográfica da Infraestrutura de Transportes no Brasil. In: CONGRESSO BRASILEIRO DE CARTOGRAFIA, 27. Anais. Rio de Janeiro: 2017.

COSTA, G. C.; SILVA, D. C.. Pré-sinalização de pontos de apoio em aerofotogrametria com câmeras de pequeno formato. In: SIMPÓSIO BRASILEIRO DE CIÊNCIAS GEODÉSICAS E TECNOLOGIAS DA GEOINFORMAÇÃO, 4. Anais. Recife: 2012.

DISPERATI, A. A.. Obtenção e uso de fotografias aéreas de pequeno formato. Curitiba: UFPR, 1991.

FELGUEIRAS, C. A.. Modelagem numérica de terreno. São José dos Campos: INPE, 2001.
LUCIEER, A.; ROBINSON, S.; TURNER, D.; STEVE, H. A.; KELCEY, J.. Using a Micro-UAV for ultra-high resolution multi-sensor observations of Antarctic moss beds. International Archives of the Photogrammetry, Remote Sensing and Spatial Information Sciences, v.39, 2012

LUZ, C. C.. Avaliação da Exatidão Absoluta de Ortofoto Obtida por meio de Dados Brutos Oriundos de Veículos Aéreos Não Tripulados (SISVANT). Dissertação (Mestrado em Ciências Geodésicas) - Universidade Federal do Paraná. Curitiba, 2015.

MELESSE, A. M.. Remote Sensing Sensors and Applications in Environmental Resources Mapping and Modelling. Sensor, v.7, p.3209-3241, 2007.

MONTOYA, C. A. H.. Incertezas, Vulnerabilidade e Avaliação de Risco Devido a Deslizamento em Estradas. Tese (Doutorado) - Universidade de Brasília, Brasília, 2013.

PONTES, A.. Avaliação da Variabilidade Espacial de um Talude Através de Investigações Geológico-Geotécnicas Diretas e Indiretas. Dissertação (Mestrado) - Universidade Federal do Paraná, Curitiba, 2017.

TREVIZOLLI, M.; FURMAN, J.; ZONTA, J.; PASSINI, L.; SESTREM, L.; FARO, V.. Mapeamento dos Movimentos de Massa de Solo em um Talude Rodoviário da Serra do Mar Brasileira: PR/SP. In: CONGRESSO NACIONAL DE GEOTECNIA, 16. Anais. Açores: 2018.

A CBPC - Companhia Brasileira de Produção Científica (CNPJ: 11.221.422/0001-03) detém os direitos materiais desta publicação. Os direitos referem-se à publicação do trabalho em qualquer parte do mundo, incluindo os direitos às renovaç̃ões, expansões e disseminações da contribuição, bem como outros direitos subsidiários. Todos os trabalhos publicados eletronicamente poderão posteriormente ser publicados em coletâneas impressas sob coordenação da Sustenere Publishing, da Companhia Brasileira de Produção Científica e seus parceiros autorizados. Os (as) autores (as) preservam os direitos autorais, mas não têm permissão par a publiçção da contribuição em outro meio, impresso ou digital, em português ou em tradução. 